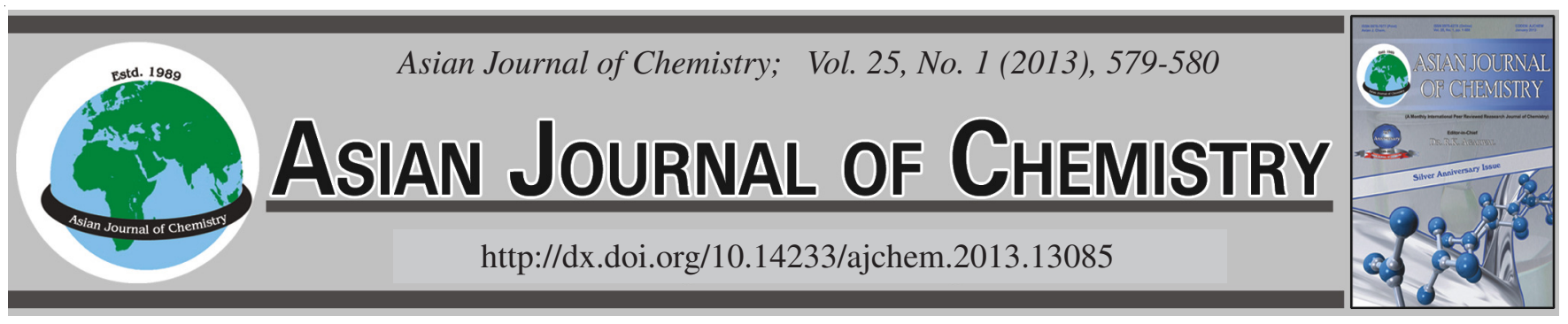

NOTE

\title{
Determination of Trace Elements and Rare Earth Elements in Gannan Navel Orange Fruit by ICP-MS
}

\author{
DingJian CAI ${ }^{1, *}$ and YukUi RuI ${ }^{2}$
}

${ }^{1}$ Institute of Material and Chemistry Engineering, University of Science and Technology, Ganzhou city, Jiangxi Province 341000, P.R. China ${ }^{2}$ College of Resources and Environmental Sciences, China Agricultural University, Beijing 100193, P.R. China

*Corresponding author: E-mail: caidingjian2010@ hotmail.com

(Received: 22 November 2011;

Accepted: 7 August 2012)

AJC-11932

\begin{abstract}
Gannan navel orange is a famous brand in China, but mineral element content in Gannan navel orange is not systematically studied. In present work, eight trace elements in Gannan navel orange from Jiangxi province were determined by ICP-MS. The results showed that Navel orange fruits contained many kinds of mineral elements, especially Mn, Fe and B, which should be the causes that Gannan navel orange is delicious and has a good taste.

Key Words: Trace elements, Rare earth elements, Gannan navel orange (Citrus science Osbeck), ICP-MS.
\end{abstract}

Navel orange, belongs to the Rutaceae, citrus, orange species, is mainly distrubuted in United States, Brazil, Spain, Japan, Australia, Morocco, South Africa and China. Navel orange is also known as the Orange King, which has many advantages such as high quality, seedless, juicy and bright color, is widely cultivated in the world. Navel orange is beneficial to the human body, known as "Good fruit therapy", which can soften and protect the blood vessels, promote blood circulation, lower cholesterol and blood lipids ${ }^{1}$.

South of Jiangxi province produce a large number of navel orange, known as the "navel orange home", where the navel orange products are sold all over the world, the navel orange from South of Jiangxi province are ususally called "Gannan navel orange". Although the Gannan navel orange is deliecious, mineral element content in Gannan navel orange is not systematically studied ${ }^{2-4}$.

ICP-MS is a good method to determine trace elements and rare earth elements, and have been applied to determine the content of elements of soil ${ }^{5}$, plant tissue ${ }^{6-8}$, animal meat ${ }^{9}$, edible oil ${ }^{10}$ and other food ${ }^{11}$. In this paper, eight trace elements in Gannan navel orange from Jiangxi province were determined by ICP-MS with microwave digestion.

Sample preparation and instruments: The navel orange fruits were bought from supermarket. Weigh $0.5 \mathrm{~g}$ fruit grinded into $10 \mathrm{~mL}$ of $70 \%$ nitric acid, digested with the microwave digestion instrument. After cooling, the supernatant was filtered for detecting.
Detecting methods: Test methods used the standard curve method. Diluting multi-element standard solution into concentrations of $0,10,20,50,100$ and $200 \mu \mathrm{g} \mathrm{L} \mathrm{L}^{-1}$ with $1 \%$ $\mathrm{HNO}_{3}$ as the standard series of working fluid to determine the contents of Mn, Fe, Mo, B, La, Dy, Eu and Pr.

Navel orange fruits contains many kinds of mineral elements, especially Mn (1250.84 ng/g), Fe (21721.84 ng/g) and B (3138.02 ng/g), but little Mo (5.80 ng/g). There are usually less rare earth elements in soil, so contents of La, Dy, Eu and Pr were much lower than the above elements Table-1.

\begin{tabular}{cccc}
\multicolumn{4}{c}{ TABLE-1 } \\
\multicolumn{4}{c}{ CONCENTRATIONS OF TRACE ELEMENTS } \\
\multicolumn{4}{c}{ IN NAVEL ORANGE FRUITS $\left(\mathrm{ng} \mathrm{g}^{-1}, \mathrm{n}=4\right)$} \\
\hline Elements & Content & Elements & Content \\
\hline $\mathrm{Mn}$ & 1250.84 & $\mathrm{La}$ & 55.16 \\
$\mathrm{Fe}$ & 21721.84 & $\mathrm{Dy}$ & 2.00 \\
$\mathrm{Mo}$ & 5.80 & $\mathrm{Eu}$ & 2.34 \\
$\mathrm{~B}$ & 3138.02 & $\mathrm{Pr}$ & 12.14 \\
\hline
\end{tabular}

Gannan navel orange, as a famous brand, contains much Mn, Fe and B, which should be the causes why Gannan navel orange is delicious and has a good taste.

\section{REFERENCES}

1. http://baike.baidu.com/view/230961.htm

2. X.M. Guo, J.M. Wang, S.F. Min, Z.H. Zhang, L.C. Cui and B.L. Zhong, Acta Agric. Boreali-occidental Sinica, 20, 127 (2011).

3. http://baike.baidu.com/view/341493.htm 
4. K.-J. Wang, X.-C. Wu, J.-L. Zhong and X.-Z. Luo, Food Sci., 32, 24 (2011).

5. Y.-K. Rui, X.-B. Kong and J. Qin, Spectrosc. Spectral Anal., 27, 1201 (2007).

6. Y.-K. Rui and G.Q. Qu, Spectrosc. Spectral Anal., 29, 819 (2009).

7. A.B. Yilmaz and L. Yilmaz, Food Chem., 1664 (2007).

8. Y.-K. Rui, Y.-L. Hao and F.-S. Zhang, Spectrosc. Spectral Anal., 27, 2111 (2007).
9. V.F. Marijic and B. Raspor, Toxicol. Lett., 168, 292 (2007).

10. Y.K. Rui, H.X. Zhang, J. Guo, K.L. Huang, B.Z. Zhu and Y.B. Luo, Agro Food Ind. Hi-Tech., 17, 35 (2006).

11. Y.-K. Rui, F.-S. Zhang and J.-B. Shen, Phyton-Int. J. Exp. Botany, 78, 101 (2009). 